Results: In children with SLE a significant increase in the content of total cholesterol $(5.56 \pm 0.36 \mathrm{mmol} / \mathrm{l})$ and a decrease in HDL-cholesterol levels $(0.94 \pm 0.18$ $\mathrm{mmol} / \mathrm{l})$ were found in comparison with the control group $(3.71 \pm 069 \mathrm{mmol} / \mathrm{L}$ and $1.29 \pm 0.33 \mathrm{mmol} / \mathrm{l}$, respectively).

A significant $(p<0.05)$ decrease in the concentration of ApoA (85.1 [59.8; 94.9] $\mathrm{mg} / \mathrm{dl}), \operatorname{ApoE}(2.1[1.2 ; 3,7] \mathrm{mg} / \mathrm{dl})$ and an increase in ApoB $(59.8[51.9 ; 67.8]$ $\mathrm{mg} / \mathrm{dl}$ ) in children with SLE were found compared with the control group (127.2 [122.1; 132.3] mg/dl, 3, 2 [2.3; 5.9] mg/dl and 32.1 [19.9; 50.8] mg/dl, respectively). ApoB / ApoA> 1 was established in 7 (28\%) children with SLE.

The study found a significant $(p<0.05)$ increase in the level of intermediate (DK233, DK278) and final (MDA) LPO products in the blood serum of children with SLE in comparison with the control group, which indicates the activation of LPO processes in these patients. During the correlation analysis, a positive correlation was established between the levels of DK233, DK278 in blood serum and CRP $\left(r_{s}=0.87, p\right.$ $<0.001$ ). When studying the main indicators of the blood lipid spectrum in children with SLE, a significant increase in the serum concentration of total lipids $(p<0.01)$ and triglycerides $(p<0.001)$ was revealed when compared with the control group. When determining indicators of coagulation hemostasis, in children with SLE, a predominance of hypercoagulation was detected, accompanied by a significant increase in serum fibrinogen level $(5.08 \pm 0.14 \mathrm{~g} / \mathrm{l})$ and an increase in platelet level $\left(479.57 \pm 8.01^{*} 10^{9} / \mathrm{l}\right)$ in peripheral blood compared with the control group $\left(3.24 \pm 0.07 \mathrm{~g} / \mathrm{I}\right.$ and $294.23 \pm 5.39^{*} 10^{9} / \mathrm{l}$, respectively). These indicators correlated with serum CRP concentration $(r S=0.62 ; p<0.01)$ and ESR level $\left(r_{s}=\right.$ $0.73 ; p<0.01$ ). A relationship was established between elevated serum levels of fibrinogen and disease activity indicators $\left(r_{s}=0.74 ; p<0.01\right)$.

Conclusion: The atherogenic orientation of the blood lipid spectrum, characterized by hyperlipidemia, hypertriglyceridemia, hypercholesterolemia and dyslipoproteinemia in the form of a decrease in HDL-cholesterol and an increase in LDL-cholesterol, as well as an increase in ApoB/ApoA ratio> 1 and a decrease in ApoE, the activation of LPO processes and a significant decrease in ACW and $A C L$ in the serum of children with SLE are cardiovascular events risk factors (pulmonary thromboembolism, myocardial infarction and brain).

Acknowledgments: This study would not have been possible without the collaboration of numerous Belarusian pediatric rheumatologists, patients and their parents.

Disclosure of Interests: None declared

DOI: 10.1136/annrheumdis-2020-eular.6683

\section{AB1009 THE EFFICACY OF TOCILIZUMAB ON THE TREATMENT OF TAKAYASU ARTERITIS IN CHINESE CHILDREN}

\section{Wang ${ }^{1}$, H. Song ${ }^{1}$, Z. Yu ${ }^{1}$, M. Quan ${ }^{1} .{ }^{1}$ Peking Union Medical College Hospital, Beijing, China}

Background: Takayasu arteritis (TA) is the most prevalent large-vessel vasculitis in children. Patients with TA have a high mobidity and mortality.It remains a therapeutic challenge because corticosteroids monotherapy can rarely cure TAK and the relapse rate is high during $\mathrm{GC}$ tapering.

Objectives: The aim of this study is to investigate the efficacy and safety of tocilizumab (TCZ)in Chinese children with Takayasu arteritis(TAK).

Methods: We retrospectively studied 6 TAK children treated with TCZ in our hospital from July 2017 to October 2018. The demographic and clinical data, laboratory examination results and vascular imaging data were collected.

Results: Six pediatric patients with critical or refractory TAK treated with TCZ were analyzed, including 3 males and 3 females. The diagnosis age was ranging in age from 2 to 13 years(median age:7 years). Three patients were initially treated with TCZ and Mycophenolate Mofetil(MMF) as the first-line regimen without corticosteroid or with a quite rapid GC taper duration,two of which had lifte-threatening coronary arteries involved and heart failure.The other three paitients were swcithed to TCZ from conventional disease modifying anti-rheumatic drugs (DMARDs) or other biologics due to being refractory to them and recurrent relapses. Four patients were given TCZ at 4 weeks regular intervals for 10 to 22 months, while two patients withdrew TCZ because of disease deterioration and unbearable abdominal or chest pain after the second dose.After 6 months follow-up,four patients experienced significant clinical and biological improvement with angiographically progression in one patient. A corticosteroid-sparing effect is obvious. Drug-related side effects occur in 1 patients manifesting as a mild elevated liver fuction. Neither neutropenia nor infection was observed.

Conclusion: Our study shows a clinical, biological, and radiological response in patients with refractory TAK treated with TCZ.

References :

[1] Hellmich B, Agueda A, Monti S,et al.2018 Update of the EULAR recommendations for the management of large vessel vasculitis. Ann Rheum Dis 2019;0:1-12. doi:10.1136/annrheumdis-2019-215672.

[2] BravoMancheño B, Perin F, Guez Vázquez Del ReyMDMR, García Sánchez A, Alcázar Romero PP. Successful tocilizumab treatment in a child with refractory Takayasu arteritis.Pediatrics 2012;130(6):e1720-724.
[3] Goel R, Danda D, Kumar S, Joseph G. Rapid control of disease activity by tocilizumab in 10 «difficult-to-treat» cases of Takayasu arteritis. Int J Rheum Dis 2013;16(6):754-61.

[4] Cañas CA, Cañas F, Izquierdo JH, Echeverri A-F, Mejía M, Bonilla-Abadía F, et al. Efficacy and safety of anti-interleukin 6 receptor monoclonal antibody (tocilizumab) in Colombian patients with Takayasu arteritis. J Clin Rheumatol Pract Rep Rheum Musculoskelet Dis 2014;20(3):125-9.

[5] Batu ED, Sönmez HE, Hazırolan T, Özaltın F, Bilginer Y, Özen S. Tocilizumab treatment in childhood Takayasu arteritis: case series of four patients and systematic review of the literature. Semin Arthritis Rheum 2017 Feb;46(4):529-35

Disclosure of Interests: None declared

DOI: 10.1136/annrheumdis-2020-eular.5778

\begin{tabular}{|l}
\hline AB1010 \\
CLINICAL SPECTRUM AND IMMUNE ANALYSIS \\
OF PATIENTS WITH CRYOPYRIN-ASSOCIATED \\
AUTOINFLAMMATORY SYNDROME IN TAIWAN
\end{tabular}

C. Y. Wu ${ }^{1}$, P. S. Chu ${ }^{1}$, H. Y. Yang ${ }^{2} .{ }^{1}$ Linkou Chang Gung Memorial Hospital, Pediatric Allergy, Asthma and Rheumatology, Taoyuan city, Taiwan, Republic of China; ${ }^{2}$ Linkou Chang Gung Memorial Hospital, Department of Nephrology, Taoyuan city, Taiwan, Republic of China

Background: Cryopyrin-associated periodic syndromes (CAPS) are emerging autoinflammatory diseases with available treatment. No reports have yet been reported from Taiwan.

Objectives: We reviewed cases suspected with CAPS to identify its existence in Taiwan.

Methods: Genomic DNA from one hundred and ten cases with symptom signs suggestive of CAPS(1) between 2016-2019 were sent for NLRP3 gene analysis Clinical presentations, laboratory data, treatment regimens, as well as inflammasome activities were analyzed among those treated in a tertiary medical center in northern Taiwan.

Results: Among the 110 cases sequenced, 16 of them were found to carry mis sense mutations within the NLRP3 gene. Fourteen cases harbored known pathogenic genetic variants (c.1316C>T; c.1574A $>$ T; and c.907G $>C$ ) and two carried novel NLRP3 missense mutations (c.210G>A, c. $1371 \mathrm{G}>\mathrm{T})(2)$ with unknown pathophysiological roles. Through chart review, chronic urticarial, systemic juvenile idiopathic arthritis, Behcet's disease and refractory Kawasaki disease were most likely diagnosed before genetic analysis were arranged. As compared to chronic infantile neurological, cutaneous and articular syndrome (CINCA) and Muckle-Wells syndrome (MWS), familial cold autoinflammatory syndrome (FCAS) was the most frequently observed clinical presentation. Plasma serum amyloid $\mathrm{A}(S A A)$ and IL-1b were both significantly elevated among the cases diagnosed with CAPS as compared to the controls $(p<0.05)$. IL-18, on the other hand, showed no significant differences between the groups. While the presence of LPS without ATP significantly increased the level of IL-1b in the PBMC stimulation test, IL-18 were significantly elevated in the confirmed CAPS with or without ATP upon LPS stimulation (all $\mathrm{p}<0.05)$. Caspase 1 activity were also tested positive among the cases with CAPS Furthermore, we compared the immune profiles between those CAPS cases harboring pathogenic mutations with the 2 harboring unreported NLRP3 missense mutations and discovered that the PBMC stimulation test in cases with c.210G $>A$ and c.1371G>T mutation did not differ from the healthy controls.

Conclusion: The number of NLRP3 gene alterations among patients suspected with CAPS in Taiwan is not low. In order to identify potential patients for proper medical intervention in the future, physician awareness, genetic testing as well as functional analysis are important.

\section{References:}

[1] Kuemmerle-Deschner JB, Ozen S, Tyrrell PN, Kone-Paut I, Goldbach-Mansky R, Lachmann $\mathrm{H}$, et al. Diagnostic criteria for cryopyrin-associated periodic syndrome (CAPS). Ann Rheum Dis. 2017;76(6):942-7.

[2] Van Gijn ME, Ceccherini I, Shinar Y, Carbo EC, Slofstra M, Arostegui JI, et al. New workflow for classification of genetic variants' pathogenicity applied to hereditary recurrent fevers by the International Study Group for Systemic Autoinflammatory Diseases (INSAID). J Med Genet. 2018;55(8):530-7

Disclosure of Interests: Chao-Yi Wu Speakers bureau: Abbvie, Boehringer Ingelheim International $\mathrm{GmbH}$, Nestle, Pi-Shuang Chu: None declared, Huang-Yu Yang: None declared

DOI: 10.1136/annrheumdis-2020-eular.5072

$\mathrm{AB} 1011$

LONG TERM FOLLOW-UP OF THE PATIENTS WITH ANTI NUCLEAR ANTIBODY POSITIVITY WHO HAD INITIALLY NO IDENTIFIABLE RHEUMATIC DISEASES

M. Yildiz ${ }^{1}$, I. Altun ${ }^{1}$, G. Yilmaz ${ }^{1}$, A. Aliyeva ${ }^{1}$, F. Haslak ${ }^{1}$, O. Koker ${ }^{1}$, A. Adrovic ${ }^{1}$, S. Sahin ${ }^{1}$, K. Barut ${ }^{1}$, O. Kasapcopur ${ }^{1} .{ }^{1}$ Istanbul University-Cerrahpasa, Pediatric Rheumatology, Istanbul, Turkey 